\title{
ERRATUM
}

Kumarasamy Thangaraj · Vempati Sridhar

Toomas Kivisild · Alla G. Reddy · Gyaneshwer Chaubey

Vijay Kumar Singh · Suminder Kaur · Pooja Agarawal

Amit Rai · Jalaj Gupta · Chandana Basu Mallick

Niraj Kumar · Thrimulaisamy P. Velavan

Rajanbabu Suganthan · Divi Udaykumar

Rashmi Kumar · Rachana Mishra · Arif Khan

Chitikineni Annapurna · Lalji Singh

\section{Different population histories of the Mundari- and Mon-Khmer-speaking Austro-Asiatic tribes inferred from the mtDNA 9-bp deletion/insertion polymorphism in Indian populations}

Published online: 13 January 2006

(C) Springer-Verlag 2006

\section{Hum Genet (2005) 116:507-517}

In the May 2005 issue of the Journal, in the article entitled "Different population histories of the Mundariand Mon-Khmer-speaking Austro-Asiatic tribes inferred from the mtDNA 9-bp deletion/insertion polymorphism in Indian populations," by Thangaraj et al. (116:507-517), there were three typographical errors, one each in text, table 2 and figure 3 :

1. In the 'Electronic database information' heading in the third line on page 515, "for mtDNA HVS-I, accession numbers AY255133-AY255180" should be "for mtDNA HVS-I, accession numbers AY368704AY368863".

2. In Table 2 on page 511, the HVS-I motif of haplotype H3 "223-156-274-320-360" should be "223-256-274320-360".

3. The 22 Nicobarese of B5a1 haplogroup in Figure 3 on page 515 should have the additional mutation 13145 along with 11881 and 13395 (fig. 1). Our reanalysis did not exhibit any further discrepancies with our original sequence data. The authors regret these errors.
The original article can be found at http://dx.doi.org/10.1007/ s00439-005-1271-6

K. Thangaraj · V. Sridhar · A. G. Reddy · G. Chaubey

V. K. Singh $\cdot$ S. Kaur $\cdot$ L. Singh $(\bowtie)$

Centre for Cellular and Molecular Biology, Uppal Road,

Hyderabad 500 007, India

E-mail: lalji@ccmb.res.in

Tel.: +91-40-27160789

Fax: +91-40-27160591

T. Kivisild

Estonian Biocenter, Riia23, Tartu, 51010 Estonia

P. Agarawal · T. P. Velavan · D. Udaykumar Institute of Microbiology \& Biotechnology, Barkatullah University, Bhopal, India

A. Rai $\cdot$ N. Kumar

Department of Biotechnology, VBS Purvanchal University, Jaunpur, India
J. Gupta $\cdot$ R. Suganthan · R. Kumar

Department of Biotechnology,

Bundelkhand University, Jhansi, India

C. B. Mallick

Department of Biotechnology, APS University,

Rewa, India

R. Mishra

Department of Biotechnology,

Allahabad Agricultural University,

Allahabad, India

A. Khan

Department of Bioscience, Sardar Patel University,

Vallabh Vidyanagar, India

C. Annapurna

Department of Biotechnology,

Kandaswamy Kandars College,

P. Velur, India 


\section{B5a1}

11881

13145

13395

22Nic

Fig. 1 The phylogenetic position of 22 Nicobarese samples in B5a1 haplogroup with an additional mutation 13145 